\title{
Endoscopic sphenoid sinus anatomy in View of Transsphenoidal Surgery: Standardized Way-point Cadaver Dissection
}

\author{
Original Mostafa Ismail ${ }^{a, b}$, Balegh Abdelhak $^{b}$, Olaf Michel $^{a}$ \\ Article \\ ${ }^{a}$ Department of Otorhinolaryngology, University Hospital Brussels, Vrije Universiteit \\ Brussel, B-1090 Brussels, Belgium \\ ${ }^{b}$ Department of Otorhinolaryngology, Minia University Hospital, Minia University, Egypt
}

\begin{abstract}
Objectives: In the view of continuous evolution in surgical techniques and instrumentation, cadaveric dissection is still the golden key for improving surgical skills and familiarity required for surgery in such critical regions with complicated anatomical details. We present an anatomical cadaveric dissection study to describe endoscopic anatomy of the sphenoid sinus using a waypoint stepwise dissection procedure.

Patients and Methods: Cadaveric dissection was conducted progressively in twenty fresh cadavers simulating endoscopic endonasal transsphenoidal approach. Our standardized waypoint procedure was followed in all specimens determining its role as a base for surgical training in such region. Anatomical variations including; level of the sphenoid sinus ostium, sphenoid peumatization, inter-sphenoid septation and intra-sphenoid bony landmarks and measurements were evaluated. Results: The standardized waypoint cadaver dissection procedure in sphenoid sinus region provided an accurate surgical orientation and relationship between anatomical landmarks founding an ideal conception for the safe and efficient surgery. Our measurements showed significant variations related to sphenoid sinus ostium, peumatization and intra-sphenoid bony landmarks.

Conclusion: Current study emphasizes the role of specialized waypoint training on cadavers for more detailed knowledge of the anatomy of challenging regions providing surgeon with a convenient surgical experience and familiarity. Although several anatomic variations were recorded in our series, it is considered as a good surgical training expedient for the alterations of anatomical structure in live surgery.
\end{abstract}

Key Words: Endoscopic surgery, Sphenoid sinus, Transsphenoidal, Way-points

Received: 04 April 2018, Accepted: 21 May 2018

Corresponding Author: Mostafa Ismail, Minia University Hospital, Kornish El Nile St., El Minia, Minya, Egypt, Tel.: +20/086-2342502, E-mail: mostafaismai13730@yahoo.com

ISSN: 2090-0740, June 2018, Vol.19, No.2

\section{INTRODUCTION}

Auditory Anatomy has historically been a cornerstone in medical education ${ }^{[1]}$, despite of its current regression ${ }^{[2]}$. Although the dissected cadaver-based anatomy is no longer taught in several centers particularly for both undergraduate medical students and medical graduates ${ }^{[2]}$, it is not the same matter for specialized surgeons in particular, with the continuous evolution of advanced and intricate surgical approaches. Since anatomical variation is one of the challenging topics in medicine ${ }^{[3],[4]}$, the cadaver dissection seems still to fulfill most of the requirements to learn practical anatomy and surgical virtuosity ${ }^{[2]}$.

Skull base surgery is one of the most difficult subspecialties to teach and learn in between the field of neurosurgery and Otorhinolaryngology, because of variant pathology, the use of delicate instruments, endoscopic vision and the dense anatomy. Depending on the fact that knowledge of the anatomy of the central skull base, particularly the anatomical region around the sphenoid sinus, plays an important role in the stepwise surgical training for endoscopic transsphenoidal approaches, we conducted an anatomical cadaveric dissection study to define variations of the endoscopic sphenoid sinus anatomy.

We established on this knowledge a model of waypoint surgery to unify the procedure, which was orientated to the transsphenoidal midline route. In endoscopic surgical practice; to operate in the sphenoid sinus region this orientation has been reported as the standard approach for the surgical treatment of most intrasellar tumors since more than three decades ${ }^{[5],[6],[7],[8]}$. However, endoscopic transsphenoidal surgery was born only after developing an understanding of the sphenoid sinus and skull base anatomy ${ }^{[9],[10],[11]}$. The presented way-point procedure gives substantial contribution for improving surgical skills and to emphasize the importance of cadaveric dissection.

\section{MATERIALS AND METHODS:}

\section{Study design}

Twenty fresh adult cadavers with no former preservation or vascular injections were studied in 
Morgue Specialization Department in UZB, VUB, Belgium following the initial autopsy examination and approval of the UZB Medical Council. For each cadaver, bilateral endoscopic nasal dissection was performed. Endoscopic localization of the sphenoid ostium, sphenoid peumatization, septation and intrasphenoidal bony landmarks was documented using a standardized waypoint procedure.

Endoscopic dissections were performed using endoscopic sinus surgery instruments with the guidance of $18-\mathrm{cm}$ long rigid endoscope with 4-mm diameter that is used for standard endoscopic sinus surgery. A light source and a digital video camera were connected to the endoscope and images were displayed on a monitor to enable dissection. The endoscope was held by the primary surgeon in all dissections; a second surgeon could observe and give instructions. All measurements were done on a millimetric scale. All cadaveric dissections were done by an ear, nose and throat (ENT) surgeon (M.I)

According to our waypoint dissection procedure, five steps were followed along the whole dissection. Dissection was started with introduction of the endoscope through the right nostril. The posteroinferior part of the middle turbinate was dislocated laterally to widen the space between the middle turbinate and nasal septum. The endoscope then was angled rostrally, along the roof of the choana and the sphenoethmoid recess, following the posteroinferior end of both middle and superior turbinates till reaching sphenoid ostium with gentile lateralization of the superior turbinate, which had to be performed in some specimens (waypoint; 1). The same procedure was repeated on the left side. At this stage we recorded; distance between the posteroinferior end of the middle turbinate and the inferior aspect of the sphenoid sinus ostium, relationship of the ostium to the posterior end of the superior turbinate and shape of the sphenoid sinus ostium (Fig.1).

After identification of the sphenoid cavity, the nasal septum was separated from the sphenoid rostrum with removal of the posterior portion of the nasal septum (about $1.5-2 \mathrm{~cm}$ ) to allow a wide binasal approach (waypoint; 2 ), (Fig.2). The nasal mucosa was detached from the vomer, anterior and inferior walls of the sphenoidal sinus and then dissected laterally (waypoint; 3), (Fig.3). A total sphenoidotomy with removal of the whole anterior wall of the sphenoid sinus was performed (waypoint; 4). Once be inside the sphenoid sinus, the number of inter-sphenoid sinus septa and its orientation were recorded (Fig.4).

Subsequently, after removal of the inter-sphenoid sinus septum/ septa, the posterior and lateral walls of the sphenoid sinus were now visible, with the sellar floor at the center, tuberculum sellae and sphenoidal planum above it, and the intra-sphenoidal clival recess below. Laterally, the upper (parasellar) and lower (infrasellar) carotid prominences as well as the optic prominence can be seen with the lateral optic-carotid recess in between (waypoint; 5), (Fig.5). Taken together all previous landmarks, the type of sphenoid sinus peumatization was determined. Additionally, inter-carotid distance was recorded at the level of the upper and lower carotid prominences as well as the inter-optic distance at the level of optic recess.

\section{RESULTS}

When following our standardized 5 waypoints to the central skull base, endoscopic dissection could be conducted focusing on direct access to the sphenoid sinus along with a panoramic endoscopic orientation and identification of the anatomical landmarks when moving from way-point to another way-point. Anatomical variations of the recorded landmarks were determined along the entire series of cadaveric dissection, and it was as following:

\section{Sphenoid ostium}

For all sphenoid ostia of our specimens except one with conchal peumatization $(n=38)$, the posteroinferior end of the middle turbinate was chosen as a reference landmark for localizing sphenoid ostium. From the inferior aspect of the sphenoid ostium, the mean distance to the posteroinferior end of middle turbinate varied between 14 to $25 \mathrm{~mm}$ with a mean of $18.9 \pm 2.3 \mathrm{~mm}$. Although oval configuration was the most common shape of sphenoid ostium, found in our specimens, $18 \%$ of ostia showed round configuration.

A total $84 \%$ of sphenoid ostia were located medial to the inferior one third of the superior turbinate, between it and nasal septum. While it was partially covered by the lower part of the superior turbinate in the remaining ostia and gentile lateralization of the superior turbinate had to be performed in such cases for direct access to the sphenoid ostium.

\section{Inter-sphenoid septation}

Evaluation of our specimens revealed no inter-sphenoid septum in only one specimen, a single inter-sphenoid septum in $75 \%$ and multiple inter-sphenoid septa $(n=2)$ in $15 \%$ of specimens. Most of inter-sphenoid septations $(67 \%)$ had paramedian orientation (right $=4$, left $=10)$, while the midline orientation was recorded in the other septations.

\section{Sphenoid pneumatization}

We classified sphenoid sinuses peumatization into sellar, presellar, and conchal types, according to classification of Hammer and Radberg ${ }^{[12]}$. In our series, the sellar type peumatization was the commonest $(65 \%)$. The presellar type was found in $30 \%$ of specimens and the conchal type was found in only one specimen. 
Intrasphenoid bony landmarks were demonstrated to be well-defined in sellar type peumatization; sellar bulge and clival indentation in the midline, carotid and optic prominences in the lateral wall with the lateral OCR in between. In presellar peumatization, all bony prominences and recesses were present but ill-defined. Carotid and optic prominence were inappreciable in all specimens with presellar pneumatization.

Carotid prominences; in specimens with sellar peumatization $(n=13)$, mean distance between medial

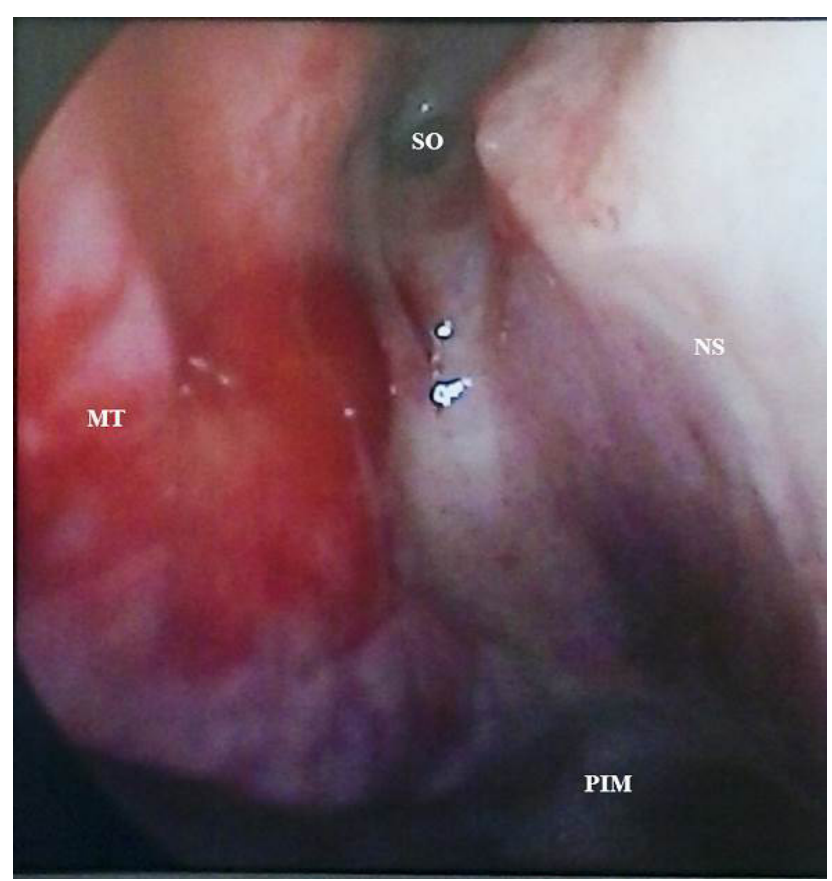

Fig. 1: Waypoint 1, approaching sphenoid sinus ostium. SO: sphenoid ostium, MT: middle turbinate, PIM: posteroinferior end of middle turbinate, NS: nasal septum.

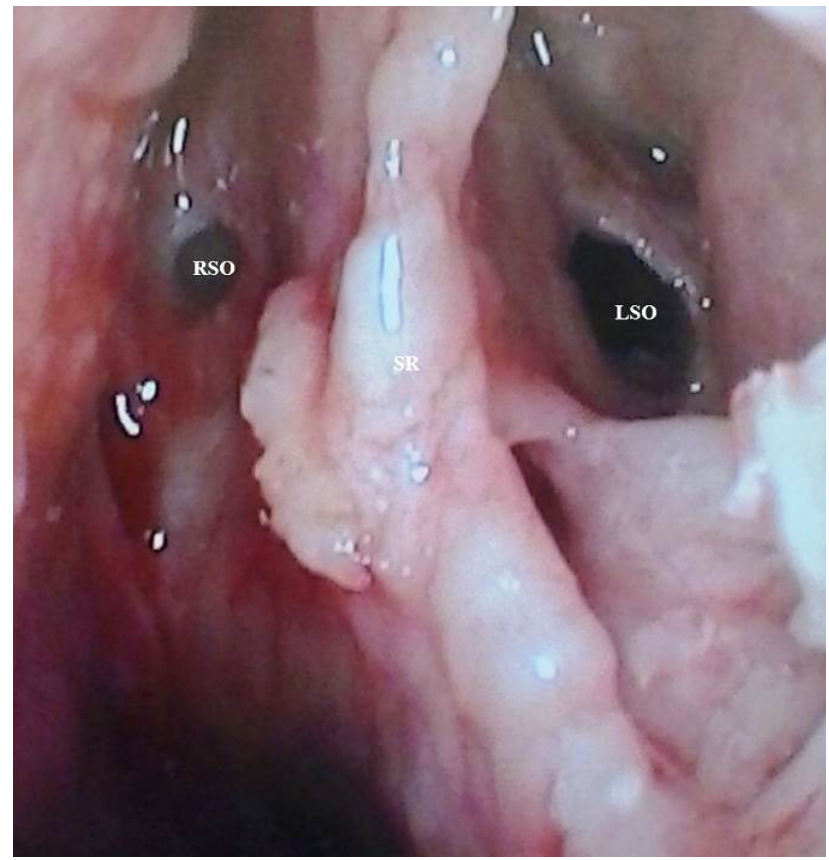

Fig. 2: Waypoint 2, binasal view of both ostia after posterior nasal septotomy. RSO: right sphenoid ostium, LSO: left sphenoid ostium, SR: sphenoid rostrum. margins of the upper carotid (parasellar) prominences was $13.8 \pm 2.8 \mathrm{~mm}$ (range: $9-19 \mathrm{~mm}$ ) and it was $13.3 \pm 3.3 \mathrm{~mm}$ (range: $7-18 \mathrm{~mm}$ ) between medial margins of the lower carotid (Paraclival) prominences.

Optic recess; in specimens with sellar peumatization $(n=13)$, Optic nerve represents the superolateral boundary of the lateral OCR (optic recess). The mean distance between medial margins of both ORs at the level of the lateral OCR was $13.4 \pm 2.9 \mathrm{~mm}$ (range: $8-19 \mathrm{~mm}$ ).

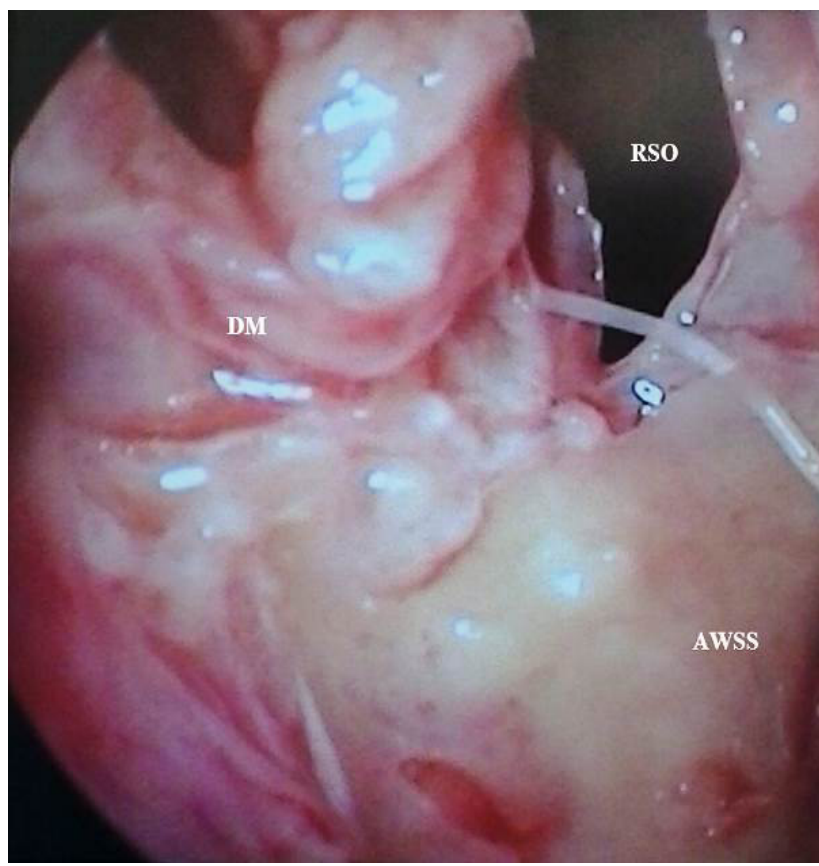

Fig. 3: Waypoint 3, dissection of nasal mucosa. RSO: righ sphenoid ostium, DM: dissected mucosa, AWSS: anterior wall of sphenoid sinus.

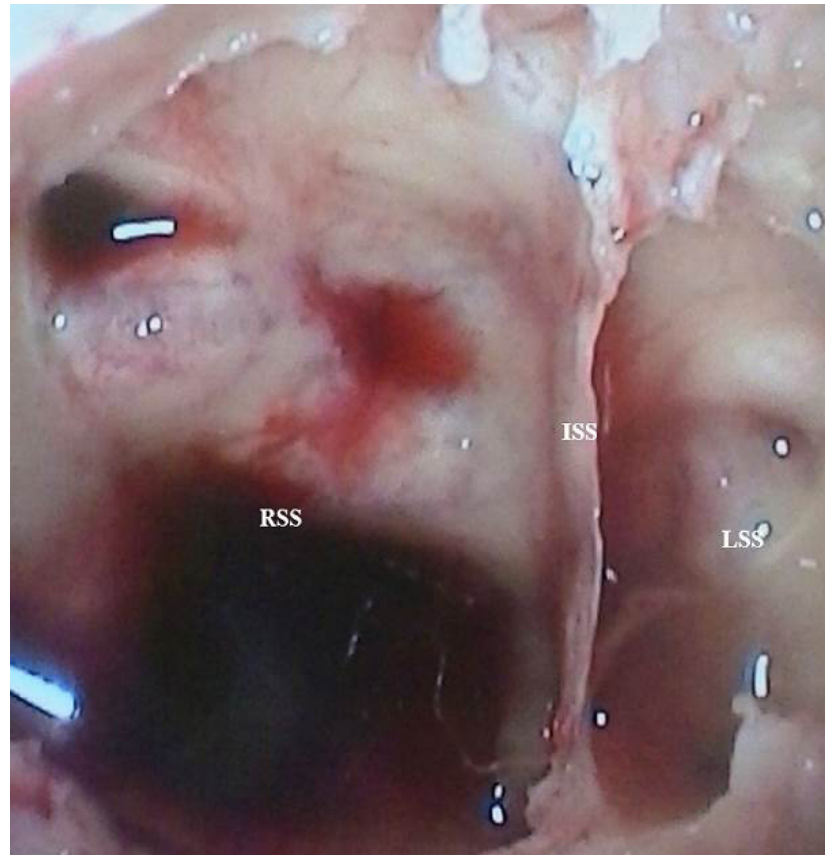

Fig. 4: Waypoint 4, total sphenoidotomy. RSS: right sphenoid sinus, LSS: left sphenoid sinus, ISS: intersphenoid septum. 


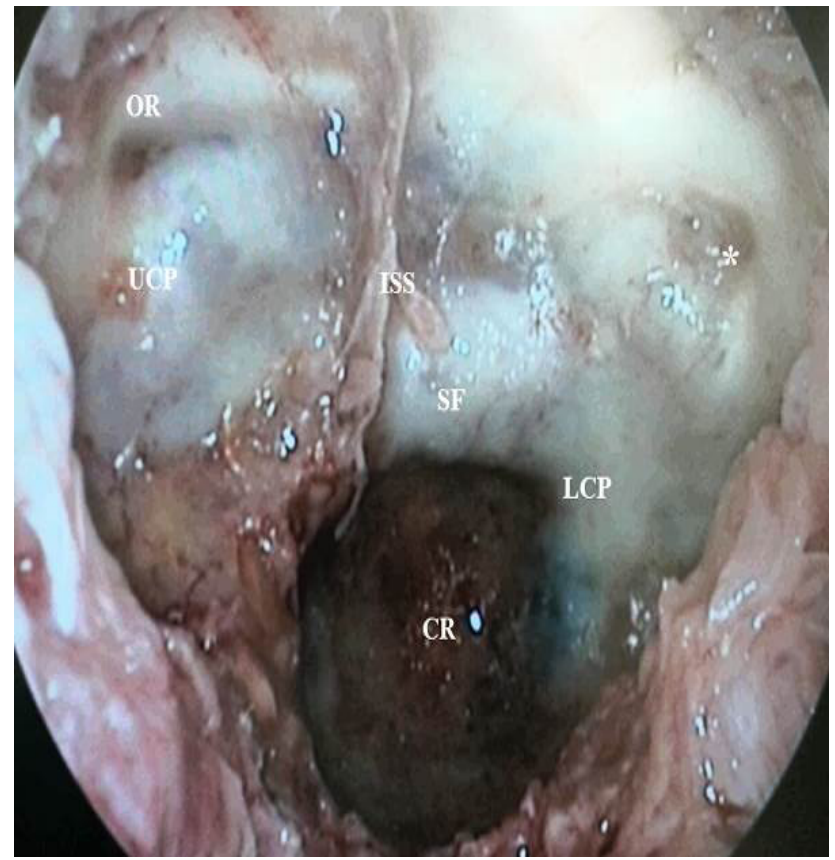

Fig. 5: Waypoint 5, endoscopic view of the sphenoid sinus after removal of intra-sphenoid septa. Intra-sphenoid bony landmarks; UCR: upper carotid prominence, LCP: lower carotid prominence, OR: optic recess, SF: sellar floor, CR: clival recess, ISS: intersphenoid septum, * (OCR): optic-carotid recess.

\section{Inter.Carotid measurement}

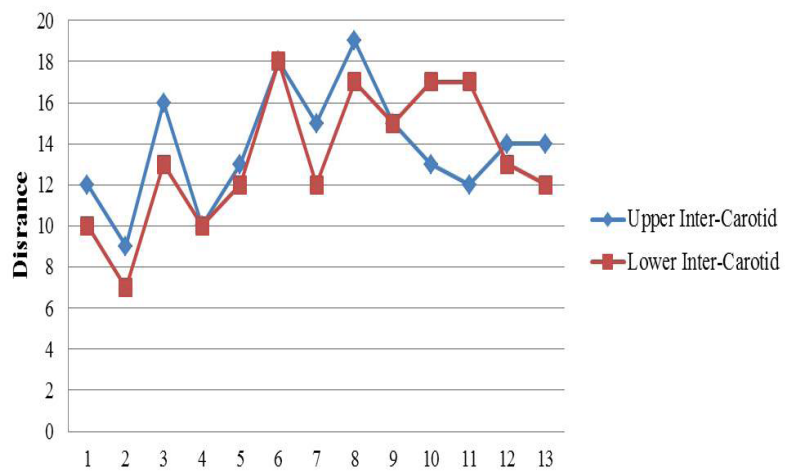

Fig. 6: Chart showing the upper and lower inter-carotid distances.

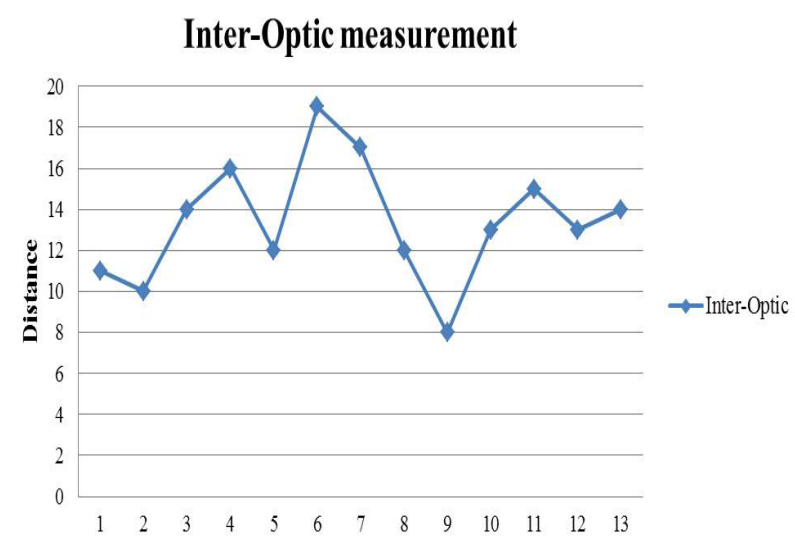

Fig. 7: Chart showing the inter-optic distance.

\section{DISCUSSION}

The As the future of surgery aims to the minimally access interventions, anatomical details previously considered as minor have become significant to the success rate of operations ${ }^{[13]}$. Most interestingly, in the last years a significant increase in public claims associated with anatomical errors was observed. This seems mainly due to lack of anatomical knowledge and imagination in younger surgeons operating on patients $^{[14]}$. Since anatomical variation is one of the most important concepts in medicine ${ }^{[3],[4]}$, the dissected cadaver remains the most powerful means of presenting and learning anatomy ${ }^{[2]}$.

Endoscopic transsphenoidal surgery was born only after developing an understanding of sphenoid sinus and skull base anatomy along with collaboration between otolaryngologists and neurosurgeons ${ }^{[0],[10],[11]}$. Earlier cadaveric studies of the sphenoid sinuses were conducted either by sagittal sectioning of cadaver heads or by en-block removal of the sphenoid sinuses and sella turcica ${ }^{[15],[16],[17]}$. Subsequently, sphenoid sinus was investigated from an endonasal point of view by the endoscopic surgeons ${ }^{[11],[18],[19],[20],[21],[22],[23],[24],[25],[26]}$. All previous endoscopic studies ${ }^{[11],[18],[26]}$ and our standardized waypoint procedure have insisted on the role of the anatomical knowledge in endoscopic surgical training of transsphenoidal approaches to avoid intraoperative complications ${ }^{[18]}$.

A lot of rationality and care have to be paid when operating in anatomical challenging surgical fields such as sphenoid sinus region. This is due to the possible variability regarding sphenoid sinus ostium, peumatization and neurovascular bony landmarks which may affect the accuracy and safety of surgery. This emphasizes the importance and feasibility of constant waypoint cadaver dissection for realizing any possible anatomical variations to anticipate planning for safe surgical approaches on real operations.

Sphenoid ostium is a natural landmark for gaining access to the sphenoid sinus. It is mandatory for the surgeon to be aware of the most probable height of the sphenoid ostium other than performing a blind palpation for getting access to sphenoid sinus ${ }^{[27]}$. The location of the sphenoid ostium has been variably reported according to different reference poin ts $^{[27],[28],[29],[30],[31],[32],[33]}$. According to Levin and May ${ }^{[34]}$, the posteroinferior end of the middle turbinate can be easily used as a standard point for finding sphenoid ostium. Although it was not recommended by some surgeons ${ }^{[27],[28]}$, it is our belief that the posteroinferior end of the middle turbinate is an easy identifiable fixed landmark which can be simply used for localizing sphenoid ostium. In our present study, sphenoid ostium could be found $18.9 \mathrm{~mm}$ (range: $1425-\mathrm{mm}$ ) above the posteroinferior end of the middle turbinate. 
Sphenoid ostium drains medially to the superior turbinate in $80 \%$ to $100 \%$ of specimens ${ }^{[27],[28],[35]}$, this was compared to our results in $84 \%$ of specimens. In some cases, the ostium cannot be visualized due to its partial coverage by the inferior part of the superior turbinate ${ }^{[4]}$, or occasionally, due to its lateral drainage to the posteroinferior end of the superior turbinate ${ }^{[27],[28]}$. Oval configuration of the sphenoid ostium is the most common appreciated shape in our series $(82 \%)$, this was similarly recorded in cadaveric study of Gupta et al. ${ }^{[27]}$. Although the circular configuration has a larger diameter than the linear one, it was recorded only in $18 \%$ of our specimens and $13 \%$ in other large cadaveric study ${ }^{[30]}$.

Sphenoid sinus is divided by complete and incomplete bony septations with various orientations $^{[36]}$. Sphenoid sinus septa were found to be variable in its number, orientation and posterior attachment. Interestingly, single inter-sphenoid septum was found in $75 \%$ of our specimens and that was the commonest finding in other cadaveric and radiological studies $^{[37],[38],[39],[40]}$. However, Sareen et al..$^{[41]}$ and Elwany et al. ${ }^{[42]}$ reported multiple inter-sphenoid septations in $80 \%$ and $73 \%$ of sinuses, respectively. Most of inter-sphenoid septations (67\%), in our series, had a paramedian orientation. The midline septa were found in $13 \%$ to $20 \%$ of sphenoid sinuses in other series $^{[37],[43],[44]}$, this emphasizes that the inter-sphenoid septum is not a dependable proof for the midline.

Sphenoid sinus is extremely variable in size and degree of pneumatization, for this the bony landmarks of the sphenoid sinus may be prominent, inappreciable or absent ${ }^{[45]}$. It is easier to identify the bony protuberances and depressions inside the well-peumatized sinuse ${ }^{[41],[46]}$. In our series, we did not record any absence of the intra-sphenoid bony landmarks except in one specimen with conchal pneumatization. The sellar bulge and clival indentation, in the midline, as well as carotid and optic prominences with the lateral OCRs in between, laterally, were either well-defined in sellar peumatization $(65 \%)$ or illdefined in presellar peumatization $(30 \%)$.

The optic nerve and carotid protuberances may be variable and sometimes they have no covering bony layer ${ }^{[15]}$. This may negatively influence the accuracy of bone removal and accordingly the safety of surgery even with using a surgical navigation. With knowledge of the possible variations of the inter-carotid and interoptic distances, the surgeon may anticipate planning for safe drilling of bone and avoiding neurovascular injury ${ }^{[47]}$.

Finally, anatomy is a living subject requires continuous practicing to be easily taught from a clinical point of view ${ }^{[2]}$. Founding a base for more standardized anatomical dissection procedures with possible reviewing of different anatomical landmarks involved in certain surgical approach, is required for setting up a new generation of competent surgeons. The way-point cadaver dissection procedure underlining accurate measurements between surgical landmarks and anatomical variations and step-by-step procedure can be considered as a good surgical training tool providing surgeon with surgical skills and familiarity required for surgery with less complication.

\section{CONCLUSION}

The utility of cadaveric dissection for surgical training is proved through our current study particularly, if it is well standardized. Endoscopic endonasal approaches through sphenoid sinus require more prudence due to the possible variability regarding sphenoid sinus ostium, peumatization and neurovascular bony landmarks. A detailed knowledge of the endoscopic anatomy of such challenging anatomical area along with specialized training on cadavers provides endoscopic surgeon with surgical skills and familiarity required for surgery with less complications.

\section{CONFLICT OF INTEREST}

There are no conflicts of interest.

\section{REFERENCES}

1. Sugand K, Abrahams P, Khurana A (2010) The anatomy of anatomy: A review for its modernization. Anatomical sciences education 3 (2):83

2. Older J (2004) Anatomy: a must for teaching the next generation. The Surgeon 2 (2):79-90

3. Ellis $H$ (2001) Teaching in the dissecting room. Clinical Anatomy 14 (2):149-151

4. Cahill D, Leonard R, Weiglein A, von Lüdinghausen M (2002) Viewpoint: unrecognized values of dissection considered. Surgical and Radiologic Anatomy 24 (3):137-139

5. Cavallo LM, Messina A, Cappabianca P, Esposito F, de Divitiis E, Gardner P, Tschabitscher M (2005) Endoscopic endonasal surgery of the midline skull base: anatomical study and clinical considerations. Neurosurg Focus 19 (1):E2

6. Cappabianca P, de Divitiis E (2003) Endoscopic endonasal transsphenoidal surgery. In: Management of Pituitary Tumors. Springer, pp 161-171

7. Liu JK, Das K, Weiss MH, Laws Jr ER, Couldwell WT (2001) The history and evolution of transsphenoidal surgery. Journal of neurosurgery 95 (6):1083-1096 
8. McDonald T, Laws Jr E (1982) Historical aspects of the management of pituitary disorders with emphasis on transsphenoidal surgery. The Management of Pituitary Adenomas and Related Lesions with Emphasis on Transsphenoidal Microsurgery New York, AppletonCentury-Crofts: $1-13$

9. Prevedello DM, Kassam AB, Gardner PA, Carrau RL, Snyderman CH (2010) Expanded endoscopic endonasal approaches to the skull base. In: Cranial, Craniofacial and Skull Base Surgery. Springer, pp 239-251

10. Prevedello DM, Thomas A, Gardner P, Snyderman CH, Carrau RL, Kassam AB (2007) Endoscopic endonasal resection of a synchronous pituitary adenoma and a tuberculum sellae meningioma: technical case report. Neurosurgery 60 (4):E401

11. Kassam A, Snyderman CH, Mintz A, Gardner P, Carrau RL (2005) Expanded endonasal approach: the rostrocaudal axis. Part I. Crista galli to the sella turcica. Neurosurgical focus 19 (1):1-12

12. Hamberger C, Hammer G, Marcusson G Experiences in transantrosphenoidal hypophysectomy. In: Transactions of the Pacific CoastOto-Ophthalmological Society annual meeting, 1960. pp 273-286

13. Pawlina W, Lachman N (2004) Dissection in learning and teaching gross anatomy: rebuttal to McLachlan. The Anatomical Record Part B: The New Anatomist $281(1): 9-11$

14. Ellis H (2002) Medico-legal litigation and its links with surgical anatomy. Surgery (Oxford) 20 (8):i-ii

15. Renn WH, Rhoton Jr AL (1975) Microsurgical anatomy of the sellar region. Journal of neurosurgery 43 (3):288-298

16. Fujii K, Chambers SM, Rhoton Jr AL (1979) Neurovascular relationships of the sphenoid sinus: a microsurgical study. Journal of neurosurgery 50 (1):31-39

17. Lang J (1989) Clinical anatomy of the nose, nasal cavity and paranasal sinuses. Thieme,

18. Unlu A, Meco C, Ugur H, Comert A, Ozdemir M, Elhan A (2008) Endoscopic anatomy of sphenoid sinus for pituitary surgery. Clinical Anatomy 21 (7):627-632

19. Catapano D, Sloffer CA, Frank G, Pasquini E, D'Angelo VA, Lanzino G (2006) Comparison between the microscope and endoscope in the direct endonasal extended transsphenoidal approach: anatomical study. Journal of neurosurgery 104 (3):419-425
20. Jankowski R, Auque J, Simon C, Marchal JC, Hepner H, Wayoff M (1992) How i do it: Head and neck and plastic surgery: Endoscopic pituitary tumor surgery. The Laryngoscope 102 (2):198-202

21. Sethi DS, Stanley RE, Pillay PK (1995) Endoscopic anatomy of the sphenoid sinus and sella turcica. The Journal of Laryngology \& Otology 109 (10):951-955

22. Carrau RL, Jho HD, Ko Y (1996) TransnasalTranssphenoidal Endoscopic Surgery of the Pituitary Gland. The Laryngoscope 106 (7):914-918

23. Cappabianca P, Cavallo LM, Colao A, de Divitiis E (2002) Surgical complications associated with the endoscopic endonasal transsphenoidal approach for pituitary adenomas. Journal of neurosurgery 97 (2):293-298

24. Cappabianca P, Cavallo LM, de Divitiis E (2004) Endoscopic endonasal transsphenoidal surgery. Neurosurgery 55 (4):933-941

25. Sethi DS, Leong J-L (2006) Endoscopic pituitary surgery. Otolaryngologic Clinics of North America 39 (3):563-583

26. Laufer I, Anand VK, Schwartz TH (2007) Endoscopic, endonasal extended transsphenoidal, transplanum transtuberculum approach for resection of suprasellar lesions. Journal of neurosurgery 106 (3):400-406

27. Gupta T, Aggarwal A, Sahni D (2013) Anatomical landmarks for locating the sphenoid ostium during endoscopic endonasal approach: a cadaveric study. Surgical and Radiologic Anatomy 35 (2):137-142

28. Kim HU, Kim SS, Kang SS, Chung IH, Lee JG, Yoon JH (2001) Surgical anatomy of the natural ostium of the sphenoid sinus. The Laryngoscope 111 (9):15991602

29. Elwany S, Yacout Y, Talaat M, El-Nahass M, Gunied A, Talaat M (1983) Surgical anatomy of the sphenoid sinus. The Journal of Laryngology \& Otology 97 (03):227-241

30. Abuzayed B, Tanriöver N, Ozlen F, Gazioğlu N, Ulu M, Kafadar A, Eraslan B, Akar Z (2009) Endoscopic endonasal transsphenoidal approach to the sellar region: results of endoscopic dissection on 30 cadavers. Turkish neurosurgery 19 (3):237

31. Campero A, Emmerich J, Socolovsky M, Martins C, Yasuda A, Agustin Campero A, Rhoton Jr A (2010) Microsurgical anatomy of the sphenoid ostia. Journal of Clinical Neuroscience 17 (10):1298-1300 
32. Hidir Y, Battal B, Durmaz A, Karaman B, Tosun F (2011) Optimum height from the roof of the choana for seeking the sphenoid ostium. Journal of Craniofacial Surgery 22 (3):1077-1079

33. Wigand ME (2008) Endoscopic Surgery of the Paranasal Sinuses and Anterior Skull Base. Thieme,

34. Levine H, May M (1993) Endoscopic sinus surgery. Thieme Medical Pub,

35. Millar DA, Orlandi RR (2006) The sphenoid sinus natural ostium is consistently medial to the superior turbinate. American journal of rhinology 20 (2):180181

36. Singh A, Germanwala AV (2011) Management of postoperative complications of skull base surgery. Operative Techniques in Otolaryngology-Head and Neck Surgery 22 (3):237-245

37. Fernandez-Miranda JC, Prevedello DM, Madhok R, Morera V, Barges-Coll J, Reineman K, Snyderman CH, Gardner P, Carrau R, Kassam AB (2009) Sphenoid septations and their relationship with internal carotid arteries: anatomical and radiological study. The Laryngoscope 119 (10):1893-1896

38. Hamid O, El Fiky L, Hassan O, Kotb A, El Fiky S (2008) Anatomic variations of the sphenoid sinus and their impact on trans-sphenoid pituitary surgery. Skull base $18(1): 9$

39. ELKammash TH, Enaba MM, Awadalla AM (2014) Variability in sphenoid sinus pneumatization and its impact upon reduction of complications following sellar region surgeries. The Egyptian Journal of Radiology and Nuclear Medicine 45 (3):705-714
40. Szolar D, Preidler K, Ranner G, Braun H, Kugler C, Wolf G, Stammberger H, Ebner F (1994) The sphenoid sinus during childhood: establishment of normal developmental standards by MRI. Surgical and Radiologic Anatomy 16 (2):193-198

41. Sareen D, Agarwal A, Kaul J, Sethi A (2005) Study of sphenoid sinus anatomy in relation to endoscopic surgery. Int J Morphol 23 (3):261-266

42. Elwany S, Elsaeid I, Thabet H (1999) Endoscopic anatomy of the sphenoid sinus. The Journal of Laryngology \& Otology 113 (02):122-126

43. Anusha B, Baharudin A, Philip R, Harvinder S, Shaffie BM (2013) Anatomical variations of the sphenoid sinus and its adjacent structures: a review of existing literature. Surgical and Radiologic Anatomy:1-9

44. Mafee MF, Chow JM, Meyers R (1993) Functional endoscopic sinus surgery: anatomy, CT screening, indications, and complications. AJR American journal of roentgenology 160 (4):735-744

45. Ramos HF, Monteiro TA, Pinheiro Neto CD, Mariani PP, Fortes FSG, Sennes LU (2011) Endoscopic anatomy of the approaches to the sellar area and planum sphenoidale. Arquivos de neuro-psiquiatria 69 (2A):232-236

46. Wang J, Bidari S, Inoue K, Yang H, Rhoton Jr A (2010) Extensions of the sphenoid sinus: a new classification. Neurosurgery 66 (4):797-816

47. Cebula H, Kurbanov A, Zimmer LA, Poczos P, Leach JL, De Battista JC, Froelich S, Theodosopoulos PV, Keller JT (2014) Endoscopic, Endonasal Variability in the Anatomy of the Internal Carotid Artery. World neurosurgery 82 (6):e759-e764 